\title{
Auditing of the phlebotomy system in medical laboratories in Port Sudan City, Sudan
}

Bashir Bashir ${ }^{1}$ and Ahmed Abdarabo ${ }^{1}$

Port Sudan Ahlia College, Port Sudan, Red Sea State, Sudan (Correspondence to: Bahir Bashir: bashirbashir17@hotmail.com).

\begin{abstract}
Background: Phlebotomy is one of the most ignored techniques in laboratory medicine and health care. It is a complicated practice that requires wide knowledge and high-level skills. Mistakes in phlebotomy can influence laboratory results (diagnosis) and affect patient care.

Aims: To appraise phlebotomists' practice and assess the extent of compliance with the guidelines and determine the frequency of errors in hospital laboratories in Port Sudan, Sudan.

Methods: A cross-sectional observational study was conducted using a structured observation scheme in 8 Sudanese public hospitals between August and September 2017. A structured questionnaire was used to assess the venepuncture procedures. Five diverse blood collections by each phlebotomist were observed at each session. We monitored 120 blood collections by 24 phlebotomists, $16(66.7 \%)$ male, and 8 (33.3\%) female, with a mean age of 31.1 years.

Results: Three of 8 phlebotomy sites were not covered by standard operating procedures (SOPs). Furthermore, phlebotomists lacked appropriate training plans. At 33.3\% of the sessions, phlebotomists did not wear gloves at all, and in $69.2 \%$ sessions, they did not use new gloves for each patient. There was a significant correlation between phlebotomists' expertise and the duration of tourniquet application.

Conclusion: This study demonstrates that SOPs were not available in some phlebotomy sites. Phlebotomists did not follow Clinical and Laboratory Standards Institute guidelines. Ongoing assessment and improvement of procedures are fundamental to ensure that the phlebotomy service operates effectively.

Keywords: phlebotomy, Port Sudan, standard operating system, tourniquet, venepuncture

Citation: Bashir B; Abdarabo A. Auditing of the phlebotomy system in medical laboratories in Port Sudan City, Sudan. East Mediterr Health J. 2020;26(7):839-845. https://doi.org/10.26719/emhj.20.006

Received: 29/11/17 accepted: 08/01/19

Copyright (c) World Health Organization (WHO) 2020. Open Access. Some rights reserved. This work is available under the CC BY-NC-SA 3.0 IGO license (https://creativecommons.org/licenses/by-nc-sa/3.o/igo)
\end{abstract}

\section{Introduction}

Phlebotomy is a technique of blood drawing in which the needle is temporarily inserted into a suitable vein (1). Phlebotomy is an ancient procedure, dating back for 3500 years to the time of ancient Egypt. The word phlebotomy is derived from Greek phlebo from phleps (vein), and tomy from tomia (to make an incision) (2). Today, phlebotomy is available primarily for enhancing diagnosis and monitoring patients' disease status. It calls for rigorous adherence to test procedures and guidelines to ensure patient safety and integrity of blood samples (3). Previously, medical technicians were responsible for blood sample collection, but in recent decades, this practice has changed and the responsibility is now shared with other health professionals (4).

Compliance in phlebotomy is challenging because there are many errors associated with the procedure (5). Quality control in the laboratory includes 3 main phases: preanalytical, analytical, and postanalytical. The preanalytical phase is the most important for phlebotomists. Every laboratory makes efforts to ensure that the routine procedure produces reliable results and that service quality is maintained (6). Agency accreditation is motivating laboratories to go beyond the standardization and quality required for pre-and postanalytical quality control to minimize errors (7). For that, most of the effort in laboratory medicine has been to raise quality and improve patient safety (8). The accreditation system of clinical laboratories based on ISO 15189 has been implemented in many countries to improve quality and competence (9). Bolenius et al. (10) and Saurav et al. (11) reported that the preanalytical phase had $46-68 \%$ of the total laboratory errors, and most of those errors were encountered during blood sample collection. In the preanalytical stage, venous blood collection is critical because it affects laboratory results. Many errors affect patient safety and health, such as patient identification, incorrect equipment use, lack of knowledge of tourniquet usage, improper skin puncturing, and no disinfectant use (12). Many factors are likely to influence the laboratory outcome, including phlebotomy education, understanding anatomy, training, and inspection of infection control procedures (13).

To the best of our knowledge, assessment of phlebotomy services in Sudan has not been reported. In this study, we aimed to assess the feasibility of phlebotomy by focusing on phlebotomists' practice and identifying the most frequently encountered errors during venous blood collection in public hospital laboratories in Port Sudan City. 


\section{Methods}

\section{Study design}

This was a hospital-based, cross-sectional observational study conducted during August to September 2017. A structured questionnaire was used (Table 1) (14) for assessment of the phlebotomy service practice. The layout of the questionnaire was intended to be simple to read with a limited number of pages, to ensure that it could be completed within the shortest possible time. The data collection was qualitative and quantitative. Confidentiality was maintained and data were solely for research purposes. Results were reported as yes/no for all phlebotomists in each setting.

\section{Study area and population}

The Red Sea Province has 16 hospitals, and 8 were chosen for this study: 4 government sector hospitals (Port Sudan Teaching Hospital, Police Hospital, Prince Osman Digna Hospital, and Seaport Corporation Hospital), 3 private sector hospitals, and a national blood bank.

\section{Study sample}

The Kish formula was used to determine the sample size for the cross-sectional study (15). We included 24 phlebotomists ( 16 male, 8 female), with a mean age of 31.1 years (range 19-48) years. Only permanently registered phlebotomists employed at the laboratory were considered for inclusion. There were 3 phlebotomists from each of the 8 hospitals. Sixteen phlebotomists had the experience [mean 6.6 (5.3) years] and competence to gain patient confidence in the venepuncture process. The checklist had 24 criteria that the phlebotomists conducted during venepuncture. The sociodemographic characteristics are summarized in Table 2. Five different venepuncture collection sessions were assessed for each phlebotomist, giving a total of 120 venous blood collections.

\section{Study performance}

Phlebotomy performance was assessed in patients who received the service after verbal consent was obtained from phlebotomist volunteers participating in the study. According to Clinical and Laboratory Standards Institute (CLSI) recommendations (7), phlebotomists were monitored for 5 different blood sample collection practices. The remarks were reviewed by independent expert evaluators and scored against a criterion-based CLSI checklist to identify preanalytical technical errors made by the phlebotomists.

\section{Study dependents}

To assess the phlebotomists' venepuncture practice performed in the laboratory, the dependents were: identification of patients; usage of tourniquet (application, and time); sterilization of the puncture sites; correct use of anticoagulant tube during blood collection; mixing blood samples for the correct time; and labelling of samples.

\section{Statistical analysis}

The findings were presented as mean (standard deviation, SD). The observational variables were estimated

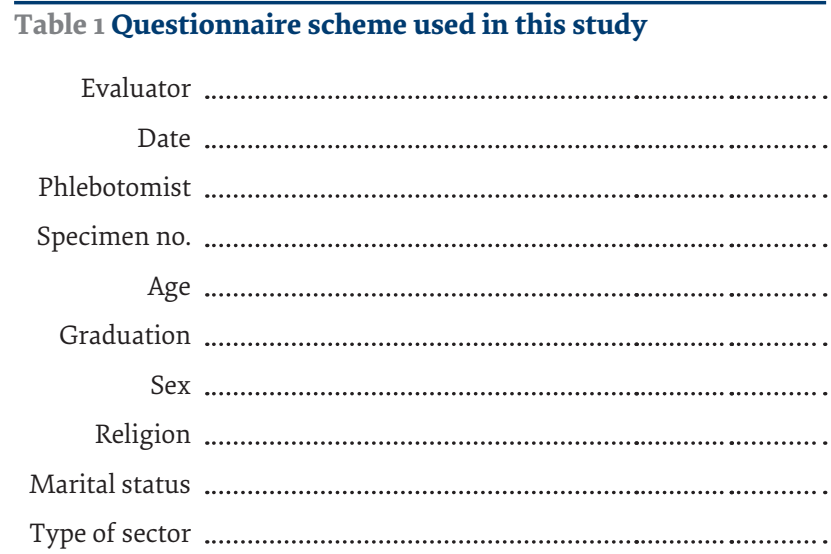

\section{Experience}

Q1. Was the patient identified according to CLSI?

Q2. Did the phlebotomist ask for permission before blood collection?

Q3. Was the tourniquet placed correctly?

Q4. Did the phlebotomist select a suitable venepuncture site?

Q5. Did the phlebotomist know how to apply the tourniquet?

Q6. Was the phlebotomist wearing gloves for each patient?

Q7. Was the venepuncture site disinfected according to guidelines?

Q8. Was alcohol allowed to evaporate before venepuncture?

Q9. Did the venepuncture site remain untouched after disinfection?

Q10. Did the phlebotomist ask the patient to clench their fists during collection?

Q11. Was the tourniquet time within CLSI recommendations?

Q12. Was the tourniquet released immediately after blood flow began?

Q13. Were the tubes used labelled in the presence of the patient?

Q14. Did the phlebotomist use a syringe to transfer blood to a vacutainer?

Q15. Did the phlebotomist used vacutainer tubes with multisampling needles?

Q16. Did the phlebotomist use a syringe to transfer blood to a vacuum tube by opening the cover?

Q17. Did the phlebotomist mix the blood gently to avoid haemolysis?

Q18. Did the phlebotomist have knowledge about sample kinds?

Q19. Were the blood coagulation samples collected according to guidelines?

Q20. Was a cotton or adhesive bandage placed over the venepuncture site after sampling?

Q21. Did the phlebotomist recap the needles and syringes?

Q22. Was the anticoagulated blood tube mixing time accepted or not?

Q23. Was there any needle stick injury?

Q24. Were syringes and needles disposed correctly after sampling? 


\begin{tabular}{|c|c|}
\hline Characteristics & $\begin{array}{l}\text { Phlebotomists } \\
\quad(n=24)\end{array}$ \\
\hline Age, mean (SD) & $31.1(8.1) \mathrm{yr}$ \\
\hline \multicolumn{2}{|l|}{ Sex } \\
\hline Male & 16 \\
\hline Female & 8 \\
\hline Education, mean (SD) & $2.79(1.95)$ \\
\hline Secondary school & 12 \\
\hline Primary school & 1 \\
\hline Graduated college & 1 \\
\hline Diploma 2 years & 10 \\
\hline Experience, mean (SD) & $6.6(5.3) \mathrm{yr}$ \\
\hline Trained & 16 \\
\hline Untrained & 8 \\
\hline \multicolumn{2}{|l|}{ Marital status } \\
\hline Single & 14 \\
\hline Married & 10 \\
\hline \multicolumn{2}{|l|}{ Sector } \\
\hline Government & 18 \\
\hline Private & 6 \\
\hline \multicolumn{2}{|l|}{ Training course } \\
\hline Yes & 0 \\
\hline No & 24 \\
\hline \multicolumn{2}{|l|}{ Workshops } \\
\hline Yes & 0 \\
\hline No & 24 \\
\hline
\end{tabular}

stepwise by comparing means by Student's $t$ test and $\chi^{2}$ test. $P \leq 0.05$ represented the minimum level of significance. Major errors were compared by $\chi^{2}$ test using SPSS version 24. Two independent expert evaluators used the same criterion-based observational evaluation checklist before and after venepuncture, to assess the phlebotomist-recorded remarks. The total scores referred to compliance with the procedural standards. Feedback from the performing laboratory on the quality of all samples collected during the study period provided additional quality control.

\section{Ethical approval}

Permission for the study was granted by the Department of Hematology, Port Sudan Ahlia College and approval was obtained from the Ministry of Health, Red Sea State, Sudan (Letter No. 44/b/1- date: 25 September 2017) and the health laboratories administration. Informed consent was obtained from all study respondents.

\section{Results}

In 5 of $8(62.5 \%)$ hospitals, the phlebotomy area had enough space for phlebotomists to carry out their work and met the minimum requirements for the materials needed. Unfortunately, during the study period, the standard operating procedures (SOPs) were not considered a part of quality control in 3 of the 8 (37.5\%) phlebotomy sites. Furthermore, most of the phlebotomists were not specialized according to their education. They worked by shift system and had no plan for future training.

\section{Findings before venepuncture session}

Sixteen of the $24(66.6 \%)$ phlebotomists received in-service training and 8 were untrained (according to the mean experience). Eleven of the $16(68.8 \%)$ trained phlebotomists worked in the government sector and $5(31.3 \%)$ worked in the private sector. Seven of the 8 $(87.2 \%)$ untrained phlebotomists worked in the government sector. This indicated that phlebotomists working in government hospitals had fewer skills and needed an intensive training programme. Nine of the 16 (56.2\%) trained phlebotomists were married and the remainder were single. This indicated that marital status had a psychological effect on the work $(P<0.042)$. Nineteen of $24(79.2 \%)$ phlebotomists had some idea of how to use the tourniquet (time and application), but $5(20.8 \%)$ of them did not know the time of tourniquet application. Twenty-three of 24 (99.2\%) phlebotomists knew about the types of specimens and anticoagulants used.

Table 3 highlights the findings of 24 phlebotomists performing 5 venepuncture procedures. In 53 of 120 (44.2\%) sessions, phlebotomists did not use $70 \%$ alcohol disinfectant. In 40 (33.3\%) sessions, phlebotomists did not wear gloves at all. In $83(69.2 \%)$ sessions, phlebotomists did not renew their gloves for each patient $(P<0.042)$. In $45(37.5 \%)$ sessions, 9 phlebotomists collected blood

\begin{tabular}{|c|c|c|}
\hline Steps & $\begin{array}{c}\text { Yes } \\
(n=120)\end{array}$ & $\begin{array}{c}\text { No } \\
(n=120)\end{array}$ \\
\hline Phlebotomist easily identified patients & 107 & 13 \\
\hline $\begin{array}{l}\text { Phlebotomist asked permission before } \\
\text { collecting blood }\end{array}$ & 105 & 15 \\
\hline Wearing gloves & 80 & 40 \\
\hline Wearing a new glove for each patient & 37 & 83 \\
\hline Cleaning the puncture site with $70 \%$ alcohol & 67 & 53 \\
\hline Collecting blood after alcohol drying & 61 & 59 \\
\hline Retouching of the cleaned site & 51 & 69 \\
\hline Request to clenching fist during collection & 80 & 40 \\
\hline Labelling of test tube before collection & 98 & 22 \\
\hline Using a syringe to transfer blood to test tube & 108 & 12 \\
\hline Using multisampling needle with holder & 66 & 54 \\
\hline $\begin{array}{l}\text { Release the tourniquet when the blood starts } \\
\text { flowing }\end{array}$ & 73 & 47 \\
\hline Duration of tourniquet based on CLSI & 75 & 45 \\
\hline Adding blood by opening the vacuum tube & 72 & 48 \\
\hline Gentle mixing to avoid haemolysis & 119 & 1 \\
\hline Mixing time of the specimen & 108 & 12 \\
\hline Apply cotton or adhesive bandage & 105 & 15 \\
\hline Collect the coagulation sample properly & 92 & 28 \\
\hline Needle stick injury & 11 & 109 \\
\hline
\end{tabular}


samples using a tourniquet for an inappropriate time (CLSI recommends 1 minute). In 75 (62.5\%) sessions, 15 phlebotomists used a tourniquet based on CLSI recommendations. The mean (SD) tourniquet time was 59.22 (14.37) seconds. There was a significant correlation between phlebotomists' expertise and duration of tourniquet application $(P<0.011)$.

\section{Findings during venepuncture}

Ninety-eight $(81.7 \%)$ of 120 blood specimen collection tubes were labelled before collection and checking the patients (Table 3). The procedure for collecting blood specimens varied among the hospitals. In 108 (90\%) of 120 sessions, phlebotomists used a syringe to collect the blood and transferred it to vacutainer tubes. In 66 (55\%) of 120 sessions, phlebotomists used multisampling needles and holders with evacuated tubes. In $72(60.8 \%)$ of 120 sessions, phlebotomists released the tourniquet when blood appeared in the syringe or test tube, demonstrating full awareness of the use of the tourniquet.

\section{Findings after venepuncture}

In $105(87.5 \%)$ of 120 sessions, phlebotomists applied cotton or an adhesive bandage to the blood collection site (Table 3 ) and $85.8 \%$ of them, especially the trained were careful in recapping the needles or syringes $(P$ < 0.001), which considerably minimized exposure to needle injury. In 119 (99.2\%) sessions, phlebotomists immediately gently mixed the blood samples after collection. In 12 (10\%) sessions, after collecting blood, phlebotomists placed the samples in a rack without mixing or with an unacceptable mixing time. The major errors demonstrated during phlebotomy are shown in Table 4.

\section{Discussion}

Poor performance of phlebotomy has adverse effects on patient safety and health. Thus, this research was conducted to assess phlebotomy practice and identify the major errors during venepunctures in public laboratories in Port Sudan City.

\begin{tabular}{|c|c|c|c|}
\hline \multirow[t]{2}{*}{ Error } & \multicolumn{3}{|c|}{ Phlebotomist $(n=24)$} \\
\hline & $\begin{array}{c}\text { Public } \\
\text { laboratory } \\
(\mathbf{n}=\mathbf{1 8})\end{array}$ & $\begin{array}{c}\text { Private } \\
\text { laboratory } \\
(\mathrm{n}=6)\end{array}$ & $\boldsymbol{P}$ \\
\hline $\begin{array}{l}\text { Did not renew the glove for } \\
\text { each patient }\end{array}$ & $13(72.2 \%)$ & $4(66.6 \%)$ & 0.042 \\
\hline $\begin{array}{l}\text { Did not use } 70 \% \text { alcohol for } \\
\text { cleaning site of puncture }\end{array}$ & $12(66.6 \%)$ & $1(16.7 \%)$ & 0.048 \\
\hline Retouching of the cleaned site & $12(66.6 \%)$ & $3(50.0 \%)$ & 0.079 \\
\hline $\begin{array}{l}\text { Collecting blood samples before } \\
\text { alcohol, dried }\end{array}$ & $8(44.4 \%)$ & $1(16.7 \%)$ & 0.238 \\
\hline $\begin{array}{l}\text { Applying a tourniquet for } \\
\text { prolonged time }\end{array}$ & $9(50.0 \%)$ & $0(0.0 \%)$ & 0.037 \\
\hline Needle stick injury & $4(22.2 \%)$ & $1(16.7 \%)$ & 0.634 \\
\hline
\end{tabular}

Phlebotomy is one of the most neglected procedures, particularly in Red Sea State. It is reported that $80 \%$ of errors occur in the preanalytical stage in clinical laboratories $(4,17,18)$. The present study showed that phlebotomists working in government hospitals had fewer skills and needed an intensive training programme. This finding agrees with Ernst (19), who proposed that the phlebotomist is stressed during work. Importantly, this study revealed that lack of planning and continuous training of the phlebotomists has a negative impact, and this may limit their career prospects. WHO also emphasized the significance of training and regular evaluation of venepuncture techniques because ineffective training and evaluation increases mistakes and lawsuits (20). Therefore, training is indispensable and motivates phlebotomists to become experts in their field committed to lifelong learning, caring for their patients, and ensuring high-quality blood specimen collection. ISO 15189 accreditation has been accepted by the laboratory personnel, because it is an internationally approved standard of laboratory medicine (21). Accreditation systems have only recently started in Red Sea State, due to a shortage of resources.

We found that $62.5 \%$ of phlebotomists had sufficient space to perform their work, which is similar to a study by Mekonon et al. (17), and both studies agree with the WHO phlebotomy guidelines (20). Regrettably, SOPs were developed in only 5 of 8 laboratories and this led to poor quality.

General safety measures should be present throughout all laboratory work, including venepuncture (7). In our study, in 40 of 120 sessions, phlebotomists did not wear gloves at all, and in 83 (69.2\%) sessions, phlebotomists did not renew their gloves for each patient. In $53(44.2 \%)$ sessions, venous blood collections were performed without using $70 \%$ alcohol or any disinfectant agent. These findings are not in accordance with the CLSI guidelines and other previous studies $(7,17)$. In 80 of 120 (66.7\%) sessions, phlebotomists requested the patient to clench their fist. This finding is inconsistent with LimaOliveria et al. (18), who have argued that this practice could contribute to changes in electrolyte concentration and skin $\mathrm{pH}$. WHO guidelines recommend that the blood puncture site must be compressed to inhibit bleeding (20); this action was achieved in 105 (87.5\%) sessions by applying an adhesive bandage. Lack of knowledge is considered to be a risk for errors. Twenty-three of 24 (99.2\%) phlebotomists knew about the types of specimens and anticoagulants used. However, they did not have full knowledge of the order in which to collect the samples, according to the CLSI guidelines (7).

Blood samples collected in tubes containing anticoagulant should be mixed by inverting gently several times to create homogeneity of anticoagulant and blood (7). In the present study, $10 \%$ of blood samples were inappropriately mixed, although this was less than the average reported by Mekonon et al. (17) and LimaOliveria et al. (18). 
Our study highlights the errors made by phlebotomists during venepuncture. These errors included not wearing new gloves for each patient, not using $70 \%$ alcohol for cleaning the puncture site, retouching the cleaned site, collecting blood samples prior to alcohol drying, and applying tourniquets for a prolonged time, thereby not complying with CLSI guidelines. However, similar findings were observed in previous studies (22-24). The duration of tourniquet application of 59.2 (14.4) seconds in our study was within the recommended time. Our finding is consistent with that of Mekonon et al. [ 51.6 (12.5) seconds] (17), but not with that of Lima-Oliveria et al. [84.4 (14.1) seconds] (18).

The current study has some limitations. We had difficulty finding literature on phlebotomists' performance of venepuncture. Moreover, we were unable to find any studies on phlebotomy in laboratories in Sudan. Eventually, we recommended a longitudinal intervention study to assess phlebotomy practice before and after an in-service training programme. We also recommend establishing a regular standardized training programme within the fields of anatomy and pathology to develop practical skills and implement the CLSI and ISO 15189 guidelines in some public hospital laboratories and expand the training gradually to other laboratories in Red Sea State.

\section{Conclusion}

Our study shows that there is a lack of SOPs in some phlebotomy practice in Port Sudan City. Also, there is some deficit in phlebotomists' skills. None of the phlebotomists undertook any training course or workshop and this reflects the extent of the negligence of phlebotomists by health administrations. However, the phlebotomists did not follow the CLSI guidelines. Ongoing assessment and improvement are fundamental to ensure that the phlebotomy service is effective. The shortage of resources is a major hurdle to improving health facilities and providing training to phlebotomy staff.

\section{Acknowledgement}

We thank all the phlebotomists who participated in the study, and all staff members in Seaport Corporation Hospital, Central Blood bank, Prince Digna hospital, Port Sudan Accident \& Emergency Hospital, Quality Medical Center, Police hospital, National Health Insurance Fund, and private clinics for their excellent assistance in conducting the research.

Funding: None.

Competing interests: None declared.

\section{Audit du système de phlébotomie dans les laboratoires médicaux de la ville de Port-Soudan (Soudan) \\ Résumé}

Contexte : La phlébotomie est l'une des techniques de médecine de laboratoire et de soins de santé les plus délaissées. Il s'agit d'une pratique complexe nécessitant de vastes connaissances et des compétences de haut niveau. Des erreurs en phlébotomie peuvent influencer les résultats des analyses de laboratoire (diagnostic) et avoir une incidence sur la prise en charge des patients.

Objectifs : Évaluer la pratique des phlébotomistes ainsi que le degré de conformité avec les lignes directrices et déterminer la fréquence des erreurs commises dans les laboratoires hospitaliers de Port-Soudan (Soudan).

Méthodes : Entre août et septembre 2017, une étude d'observation transversale a été menée dans huit hôpitaux publics soudanais à l'aide d'un système d'observation structuré. Un questionnaire structuré a été utilisé pour évaluer les procédures de ponction veineuse. Lors de chaque session, cinq prélèvements de sang différents effectués par chacun des phlébotomistes ont été observés. On a surveillé 120 prélèvements de sang effectués par 24 phlébotomistes, $16(66,7 \%)$ étant des hommes et 8 (33,3\%) femmes, dont l'âge moyen était de 31,1 ans.

Résultats : Trois des huit sites de phlébotomie n'étaient pas couverts par des modes opératoires normalisés. De plus, les phlébotomistes ne disposaient pas de plans de formation adéquats. Dans 33,3\% des sessions, les phlébotomistes ne portaient pas du tout de gants, et dans $69,2 \%$ des sessions, ils ne portaient pas de nouveaux gants pour chaque patient. Une forte corrélation a été observée entre l'expertise des phlébotomistes et la durée d'application du garrot.

Conclusion : La présente étude met en évidence la non-disponibilité de modes opératoires normalisés dans certains sites de phlébotomie. Les phlébotomistes ne suivaient pas les lignes directrices du Clinical and Laboratory Standards Institute. L'évaluation continue et l'amélioration des procédures sont essentielles pour garantir le bon fonctionnement du service de phlébotomie. 


\section{مر اجعة نظام فصد الدم في المختبرات الطبية في مدينة بورتسودان في السودان \\ بإير عبدالرمن بشير، أحمد عبدربه \\ الخلاصة}

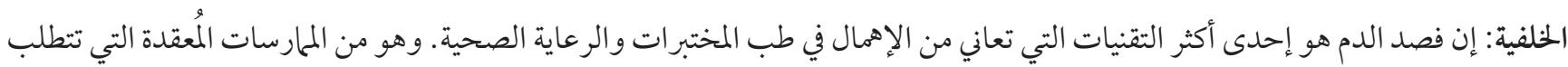

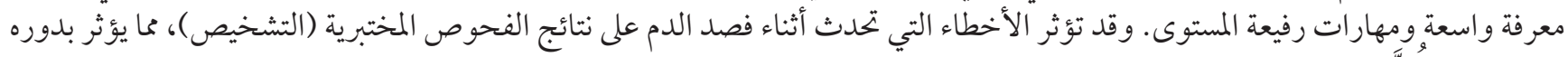
على الرعاية المقدَّمة للمرضى.

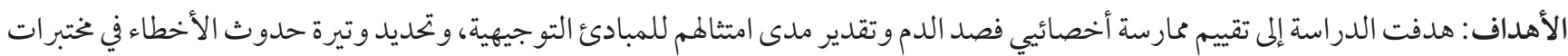
المستشفيات في بورتسودان، السودان.

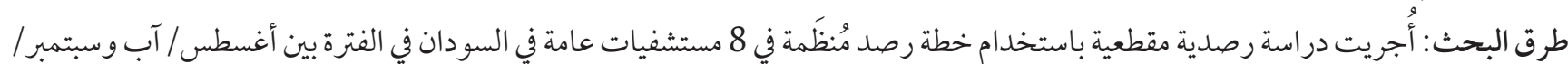

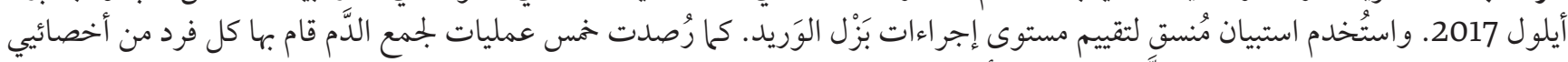

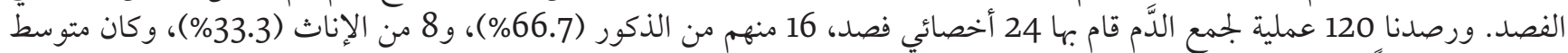
عمرهم 31.1 عاماً.

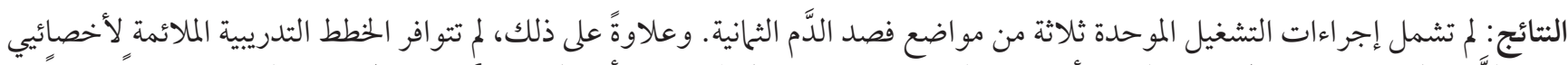

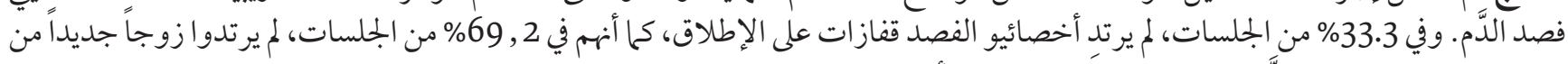

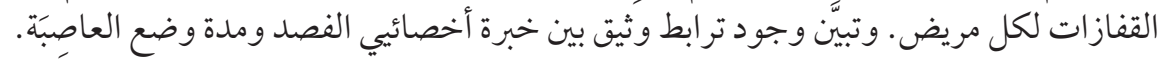

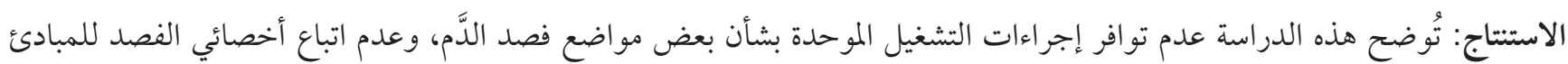

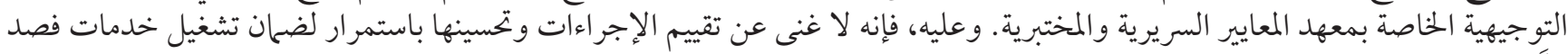
النَّم بفعالية.

\section{References}

1. Phlebotomy tutorial for medical education - WebPath [website]. (https://library.med.utah.edu/WebPath/TUTORIAL/PHLEB/ PHLEB.html, accessed 16 January 2020).

2. Warekois RS, Robinson R. Phlebotomy worktext and procedures manual. 4th edition. Saunders; 2016.

3. Ernst DJ. States fail to follow California's lead in certifying phlebotomists. Med Lab Observer. 2008 Aug;40(7):40-2.

4. Lippi G, Salvagno GL, Montagnana M, Franchini M, Guidi GC. Phlebotomy issues and quality improvement in results of laboratory testing. Clin Lab. 2006;52(5-6): 217-30. PMID:16812947

5. Cheesbrough M. District laboratory practice in tropical countries. Part 1. Cambridge: Cambridge University Press; 2002.

6. Establishment of quality system and accreditation in health laboratories report of an Intercountry workshop Thailand, 9-13 October 2006. New Delhi: World Health Organization Regional Office for South-East Asia; 2007 (https://apps.who.int/iris/handle/10665/205029, accessed 16 January 2020).

7. Procedures for collection of diagnostic blood specimens by venipuncture; approved standard. 6th edition. Wayne, PA: Clinical and Laboratory Standards Institute; 2007.

8. Lai X, Yang P, Zhang Y, Cao J, Zhang L. Analysis of factors influencing the generation of unqualified clinical samples and measures to prevent this generation. Ann Lab Med. 2012 May;32(3):216-9. http://dx.doi.org/10.3343/alm.2012.32.3.216 PMID:22563558

9. Hawkins R. Managing the pre- and post-analytical phases of the total testing process. Ann Lab Med. 2012 Jan;32(1):5-16. http:// dx.doi.org/10.3343/alm.2012.32.1.5 PMID:22259773

10. Bolenius K, Brulin C, Grankvist K, Lindkvist M, Soderberg J. A content validated questionnaire for assessment of self-reported venous blood sampling practices. BMC Res Notes. 2012 Jan 19;5:39. http://dx.doi.org/10.1186/1756-0500-5-39 PMID:22260505

11. Patra S, Mukherjee B, Das AK. Pre-analytical errors in the clinical laboratory and how to minimize them. Int. J. Bioassays. 2013;2(3):551-3. http://dx.doi.org/10.21746/ijbio.2013.03.0017

12. Lippi G, Becan-McBride K, Behúlová D, Bowen RA, Church S, Delanghe J, et al. Preanalytical quality improvement: in quality we trust. Clin Chem Lab Med. 2013 Jan;51(1):229-41. http://dx.doi.org/10.1515/cclm-2012-0597 PMID:23072858

13. Bowen RA, Hortin GL, Csako G, Otanez OH, Remaley AT. Impact of blood collection devices on clinical chemistry assays. Clin Biochem. 2010 Jan;43(1-2):4-25. http://dx.doi.org/10.1016/j.clinbiochem.2009.10.001 PMID:19822139

14. Gould DJ, Drey NS, Greedon S. Routine hand hygiene audit by direct observation: has nemesis arrived? J Hosp Infect. 2011 Apr;77(4):290-3. http://dx.doi.org/10.1016/j.jhin.2010.12.011. PMID:21316122

15. Kish L. Survey Sampling. New York: John Wiley and Sons; 1965. 
16. Mekonon WL, Abebe AT, Haile EL, Misganaw AS. Evaluation of phlebotomy service in clinical laboratory setting in Addis Ababa Public Hospitals, Addis Ababa, Ethiopia. Am J Lab Med. 2017 May;2(3):24-33.

17. Keohane EM. Blood specimen collection. In: Keohane EM, Smith LJ, Walenga JM. Rodak's clinical hematology clinical, principles and applications. 5th edition. St. Louis: Elsevier Saunders; 2016:25.

18. Oliveira GL, Guidi GC, Salvagno GL, Montagnana M, Rego FG, Lippi G, et al. Is Phlebotomy Part of the Dark Side in the Clinical Laboratory Struggle for Quality? Lab Med. 2012 Aug;43(5):172-6. https://doi.org/10.1309/LMZ7YARD6ZSDIID

19. Ernst C. Phlebotomy training: Does your program pass the test. MLO Med Lab Obs. 2011 Sep;43(9):36-38. PMID:21941998

20. Guidelines on drawing blood: best practices in phlebotomy. Geneva: World Health Organization; 2010 (https://www.who.int/ infection-prevention/publications/drawing_blood_best/en/, accessed 17 January 2020).

21. Sciacovelli L. Aita A, Padoan A, Antonelli G, Plebani M. ISO 15189 accreditation and competence: a new opportunity for laboratory medicine. J Lab Precis Med. 2017 Sep;2(9):79. http://dx.doi.org/10.21037/jlpm.2017.09.05

22. Shashi Upreti, Sanjay Upreti, Rani Bansal, Nadia Jeelani, and Vinay Bharat. J Clin Diagn Res. 2013 Nov;7(11):2491-3.

23. Nagat D. Prevalence of preanalytical errors in clinical chemistry diagnostic labs in Sulaimani city of Iraqi Kurdistan. PloS One. 2017 Jan 20;12(1):e0170211. http://dx.doi.org/10.1371/journal.pone.0170211 PMID:28107395

24. Magnette A, Chatelain M, Chatelain B, Ten Cate H and Mullier F. Pre-analytical issues in the haemostasis laboratory: guidance for the clinical laboratories. Thromb J. 2016 Dec 12;14:49. http://dx.doi.org/10.1186/s12959-016-0123-z PMID:27999475 